\title{
Modularity and Intellectual Property Protection
}

\section{Citation}

Baldwin, Carliss Y., and Joachim Henkel. "Modularity and Intellectual Property Protection." Strategic Management Journal 36, no. 11 (November 2015): 1637-1655. (Was Harvard Business School Working Paper, No. 14-046, December 2013. Revised January 2014.)

\section{Published Version}

http://onlinelibrary.wiley.com/doi/10.1002/smj.2303/full

\section{Permanent link}

http://nrs.harvard.edu/urn-3:HUL.InstRepos:11591705

\section{Terms of Use}

This article was downloaded from Harvard University's DASH repository, and is made available under the terms and conditions applicable to Other Posted Material, as set forth at http:// nrs.harvard.edu/urn-3:HUL.InstRepos:dash.current.terms-of-use\#LAA

\section{Share Your Story}

The Harvard community has made this article openly available.

Please share how this access benefits you. Submit a story.

\section{Accessibility}




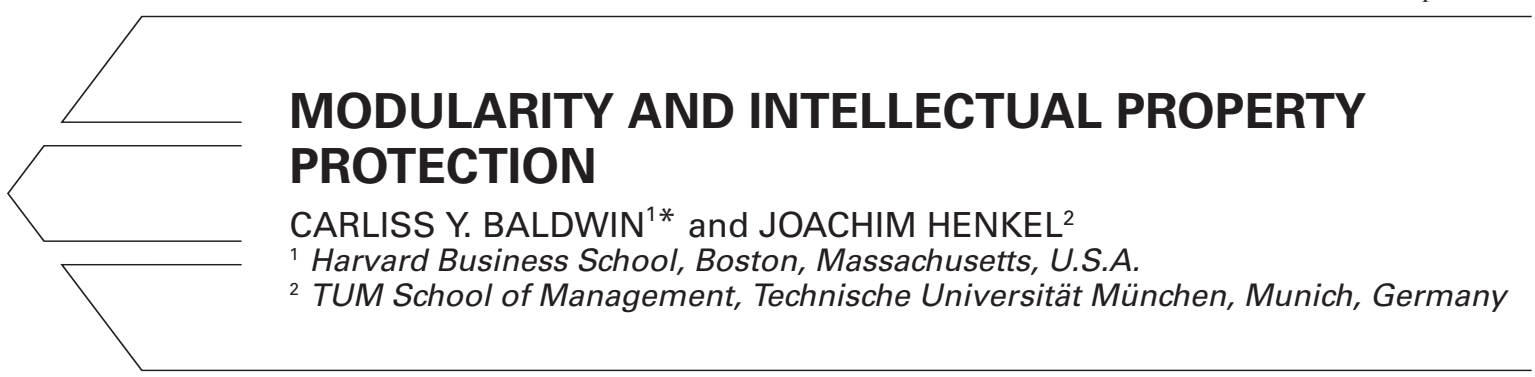

\begin{abstract}
Modularity is a means of partitioning technical knowledge about a product or process. When state-sanctioned intellectual property (IP) rights are ineffective or costly to enforce, modularity can be used to hide information and thus protect IP. We investigate the impact of modularity on IP protection by formally modeling the threat of expropriation by agents. The principal has three options to address this threat: trust, licensing, and paying agents to stay loyal. We show how the principal can influence the value of these options by modularizing the system and by hiring clans of agents, thus exploiting relationships among them. Extensions address screening and signaling in hiring, the effects of an imperfect legal system, and social norms of fairness. We illustrate our arguments with examples from practice. () 2014 The Authors. Strategic Management Journal published by John Wiley \& Sons Ltd.
\end{abstract}

\section{INTRODUCTION}

Modularity brings many technical and organizational benefits, including the division of labor, reduced cognitive complexity, and higher adaptability and evolvability (Baldwin and Clark, 2000; Garud and Kumaraswamy, 1995; Schilling, 2000; Simon, 1962). Yet, despite these well-known technical benefits that support value creation, it is not always straightforward for firms to capture value and protect their intellectual property (IP) in a modular system. In fact, the increased threat to IP has been described explicitly as a drawback of modularity, to be balanced against its various potential benefits (Ethiraj, Levinthal, and Roy, 2008; Pil and Cohen, 2006; Rivkin, 2000).

Keywords: modularity; value appropriation; intellectual property; relational contracts; clans

*Correspondence to: Carliss Y. Baldwin, Baker Library 341, Harvard Business School, Boston, MA 01263, U.S.A. E-mail: cbaldwin@hbs.edu
The risks that modularity poses to IP are illustrated by the history of IBM's System/360, the first "truly modular" computer (Ferguson and Morris, 1993). Peripheral devices such as disk drives, tape drives, and printers could be added as modules to an existing system without difficulty. While customers valued this flexibility, soon after the introduction of System/360, many new firms making peripheral devices entered the market in competition with IBM. Importantly in our context, many of these firms were started by defecting IBM employees (Pugh, Johnson, and Palmer, 1991).

In other cases, however, modularity can help to protect IP, by splitting crucial knowledge into separate modules. Consider the following historical example. In the eighteenth century, Frederick Augustus II, Elector of Saxony, maintained a monopoly on European porcelain by the simple expedient of imprisoning the inventor in a fortress in Meissen. When the inventor was close to death, Augustus ordered him to divide his knowledge between two successors. One man was

(C) 2014 The Authors. Strategic Management Journal published by John Wiley \& Sons Ltd.

This is an open access article under the terms of the Creative Commons Attribution-NonCommercial-NoDerivs License, which permits use and distribution in any medium, provided the original work is properly cited, the use is non-commercial and no modifications or adaptations are made. 
told the formula for porcelain paste; the other learned the secrets of making porcelain glaze. Thus, after the inventor died, no one individual could replicate the entire Meissen porcelain-making process (Gleeson, 1998).

In this paper, we will show that modularity can be used to protect IP by enabling companies to disperse and hide information that might otherwise be difficult to protect through the legal system. The relationship between organizational secrets and organization structure has been explored theoretically by Liebeskind (1997), Rønde (2001) and Rajan and Zingales (2001). Our analysis builds on this prior work and goes beyond it in the following ways.

First, we distinguish between trustworthy and untrustworthy types of agents. The presence of trustworthy agents in the population makes the option of "doing nothing"-i.e., banking on the possibility that there is no untrustworthy agent among the employees - relevant for the principal, in addition to ex ante licensing and setting up relational contracts. It also entails a discussion of screening and signaling in order to pick trustworthy agents. Second, we account for relationships among agents by analyzing "clans" defined as associations of individuals with common values and beliefs who act consistently in most circumstances (Ouchi, 1980). Third, in our analysis of modularity, we allow for different levels of complementarity among modules, and investigate how clans and modularity interact in determining the preferred organizational structure. Fourth, we critically evaluate the predictions of rational choice theory when applied to agents who are socialized within relationships.

Our main results are the following. For the base case of a one-module system, doing nothing is the best option for protecting the principal's IP if the percentage of trustworthy agents in the population is high. Ex ante licensing is optimal if the percentage of trustworthy agents is low, and the intensity of competition in duopoly is also low (so that the license is valuable). Establishing relational contracts with agents (i.e., paying them above their efficiency wage not to defect) dominates both doing nothing and ex ante licensing if the number of agents is low, and the percentage of trustworthy agents is below a threshold. Finally, a decline in the number of agents needed to perform the focal tasks increases the range of parameter values for which doing nothing or a relational contract is preferred to licensing.

Hiring clans of agents, or promoting their emergence among employees, is a way for the principal to mitigate the risk of expropriation. Assuming that all members of a clan act together, the presence of clans in effect reduces the number of independently acting agents among the employees. This makes both doing nothing and a relational contract more attractive relative to licensing.

Modularizing the focal technical system has similar effects to hiring clans. Each module has fewer agents than the whole system and is worth less; hence, doing nothing and relational contracts increase in value relative to licensing. This effect increases as modules exhibit higher levels of complementarity. In this context, we point out an important difference between modularity-in-use and modularity-in-production. While the former facilitates imitation and substitution (Ethiraj, Levinthal, and Roy, 2008; Pil and Cohen, 2006; Rivkin, 2000), we show that the latter mitigates the risk of expropriation of knowledge by agents.

Clans and modularity interact in an important way. As long as all members of a clan work on the same module, their protective effects against expropriation reinforce each other. But if members of a clan are spread across modules and can share their knowledge, then clan members will have access to knowledge that module boundaries could have kept hidden from them. In that case, clans partly defeat the protective effect of modularity.

Lastly, when clans or modules are asymmetric, our model-based on rational choice theoryindicates that members of larger clans and agents working on less valuable modules should be paid less. Also, cohorts of new hires that have a higher share of trustworthy agents (due to improved screening or signaling technology) should receive lower payments. We shall argue, however, that the use of rational choice theory to predict agents' behavior may not be appropriate if agents value relationships characterized by reciprocity and fairness.

Our paper is organized as follows. In the next section, we review the relevant literature. We then begin our formal analysis by introducing and analyzing the base case of a one-module system. We analyze the impact of clans and go on to study the impact of modularity and its interaction with clans. After discussing several extensions of our analysis, we provide illustrative examples from practice. 
We conclude the paper by describing the limitations of our analysis, implications for scholars and managers, and directions for future work.

\section{BACKGROUND}

Knowledge may be a source of profits and competitive advantage, so long as it cannot be expropriated, imitated, or substituted (Barney, 1991; Teece, 1986, 2000). IP rights may protect against expropriation and imitation, but vary in strength by jurisdiction and industry (Maskus, 2000; Zhao, 2006; Kyle and McGahan, 2009; Branstetter et al., 2011). When formal IP rights are weak, relational contracts may afford protection against expropriation. As we will show, they may be particularly effective in conjunction with modularity. In this section, we review the relevant strands of literature.

\section{Relational contracts in economics, law and sociology}

The economic theory of the firm is concerned with the location of boundaries between companies (Coase, 1937). Grossman and Hart (1986) and Hart and Moore (1990) developed a theory of the firm based on optimal allocation of property rights. Brynjolfsson (1994) and Arora and Merges (2004) applied their reasoning to knowledge and intellectual property. We follow Brynjolfsson in focusing on knowledge as an asset, and we follow Hart and Moore (1990) in defining "property" as the ability to exclude others from using the asset. However, like Arora and Merges (2004), we do not consider property rights to be secure.

Baker, Gibbons, and Murphy (2002) extended the Grossman-Hart-Moore theoretical framework to include so-called "relational contracts." In a relational contract, deviations from cooperative behavior can be punished by terminating the relationship. As long as the reward to deviation is less than the continuation value of the relationship, parties to the contract will cooperate without state enforcement (Gibbons and Henderson, 2012; Greif, 1998; Kreps, 1990). Relational contracts are thus self-enforcing (Baldwin, 1983; Greif, 1998; Telser, 1980). They can be modeled as repeated games (Baker et al., 2002; Bull, 1987; Kreps, 1990). In practice, they take different forms including unilateral contractual payments, bilateral contractual payments, and equity-based alliances (Arora and Merges, 2004; Oxley, 1997).
It should be noted that the concept of relational contract in economics differs from that in law and sociology. In law, for example, Macneil $(1978,1985)$ defines relational contracts as associations that have significant duration and involve close personal relationships, with "entangling strings of friendship, reputation, interdependence, morality, and altruistic desires" (Macneil, 1987: 276). In contrast, in economics and game theory, agents are assumed to be purely calculative about a continuing relationship; that is, they constantly ask the question "Is it worthwhile for me to stay in this relationship or not?" (Williamson, 1993). In what follows, we use the term "relational contract" as in economics and game theory, to mean a self-enforcing agreement between self-interested, value-maximizing agents.

However, the difference in perspectives leads to different interpretations of the concept of trust, which is a central focus of our analysis. Scholars in sociology, for example, Granovetter (1985), define trust as the expectation of noncalculative, benign action by another agent, and see it arising from a combination of embeddedness in social networks and repeated personal interaction (Uzzi, 1997). Dyer and Singh (1998) argue that informal safeguards based on trust generate greater "relational rents" than formal safeguards, but empirical support of this contention is mixed at best (Sako, 1998). Taking the economic perspective, Williamson (1993: 475-479) acknowledges that trustworthy behavior in commercial relationships can be elicited by environmental conditions, including embeddedness in social networks and cultural norms and expectations. But, he argues, such actions flow from agents' calculations of long-term self-interest. Supporting this point of view, there is evidence that transaction hazards (i.e., temptations) increase the probability of untrustworthy behavior (Poppo, Zhou, and Zenger, 2008). But there is also countervailing evidence from psychology that cost-benefit analysis does not affect dishonest behavior (Mazar, Amir, and Ariely, 2008).

In general, it is impossible to infer from actions alone whether a given agent's trustworthy behavior is motivated by calculations of long-term interest, concerns about social sanctions, personal integrity, or a combination of these factors (Poppo and Zenger, 2002; Posner, 2002). However, there is observable variation in behavior across individuals and populations. Rotter (1980) presents evidence 
that some individuals are innately more trusting and trustworthy than others. And the probability that trustworthy behavior arises from social norms and moral beliefs vs. direct payments varies across cultures and is sensitive to surrounding institutions (Bjørnskov, 2007; Meier, 2006; Yamagishi and Yamagishi, 1994). Still, one can never be 100 percent sure that the person one is dealing with is trustworthy - trust can always be abused (Granovetter, 1985).

In our model, we distinguish between agents, called "trustworthy," for whom social norms and moral beliefs are sufficient to prevent defection and agents, called "untrustworthy," who are strictly calculative and require financial compensation not to defect. We allow the percentage of trustworthy and untrustworthy agents to vary across populations, and show how the focal firm will condition its strategy on this variable. We admit that this is a crude way to capture the subtle nuances of relationships in organizations, but we believe that deciding whether to trust (vs. pay) one's agents is a true strategic choice for firms whose competitive advantage rests on protecting organizational secrets.

\section{Organizational secrets and the problem of expropriation}

In a seminal paper, Liebeskind (1997) opened up the topic of protecting organizational secrets by discussing the benefits and costs of keeping a firm's unique knowledge safe from public view. She framed secrecy as an economic tradeoff, and discussed various methods used by firms to protect their secrets. Rønde (2001) then constructed a formal model in which a principal, who needs to grant agents access to his knowledge in order to commercialize it, fears that they will expropriate it. (Rønde's agents are strictly calculative.) The principal can either grant all agents full access, or divide the task at hand and provide to each agent only the information she needs for her task.

Rajan and Zingales (2001) analyze how a principal can contain the risk of knowledge expropriation through the firm's hierarchical structure and size. In a vertical hierarchy, agents on lower levels are assumed to have limited access to the principal's knowledge due to their larger distance from the knowledge source and specialization to direct superiors. This specialization and the resulting loyalty drive the result that physical-capital-intensive industries should be characterized by steep hierarchies, while in human-capital-intensive industries flat hierarchies should prevail.

Finally, the idea of dividing knowledge in order to capture more of its value figures in Anton and Yao's (2005) model of a sale of IP subject to Arrow's (1962) information paradox. They suggest splitting the knowledge in such a way that one part is protectable and informative about the value of the IP overall, and selling this part first. They find this approach to be more profitable for the seller than a bundled sale.

\section{Clans}

One possibility for the principal to protect his knowledge from expropriation is to employ agents who defect, or stay on, in groups. Ouchi (1980) defines a "clan" as an association of individuals who have been socialized to have common values and beliefs and thus act consistently in most circumstances. Clan members who deviate may also be punished by loss of access to the clan, ostracism, or shunning. A clan "resembles a kinship network but may not include blood relations" (Ouchi, 1980: 134).

The focus of Ouchi's (1980) and most subsequent work in this context is on clan control of a firm as an alternative to market or bureaucratic control mechanisms. The firm's employees, effectively, constitute the clan. However, the clan may also be a subset of the firm's employees. In that case, the clan's goals can be incongruent to those of the firm, as, for example, in Johnson et al.'s (2002) study of international joint ventures or Groysberg and Abrahams' (2006) analysis of "liftouts" (defined as the hiring away of whole organizational units or teams). Indeed, teams whose members work closely together may become embedded in their own social network and thus develop the characteristics of a clan-more precisely, a "social-integrative clan" in the nomenclature of Alvesson and Lindkvist (1993). Alternatively, the principal may hire clans defined by observable features such as nationality or family ties.

As we will show, employing clans can both aggravate and mitigate the threat of expropriation of knowledge. As a means of protection, it is most effective in conjunction with modularity.

\section{Modularity}

According to the theory of modularity, firms can divide complex technical systems into components 
(modules) that can be designed independently but function together as a whole. Three key concepts are worth noting. First, the modular structure of a technical system is a choice that system architects make. Most complex technical systems can be designed to be more or less modular, and the boundaries between modules can be located in different places (Baldwin and Clark, 2000; von Hippel, 1990; Mead and Conway, 1980; Ulrich and Eppinger, 1994). Second, if the separation of modules is done properly, the design decisions taken with respect to one module will not affect decisions taken in other modules. Design tasks can then be allocated to different organizational units or firms (Langlois, 2002; Langlois and Robertson, 1992; Sanchez and Mahoney, 1996). Third, just as modules can be separated in terms of their underlying design decisions, knowledge about modules can likewise be separated. As long as they can access the design rules specifying the interfaces, Module A's designers do not need to have specific knowledge about Module B's internal structure (Parnas, 1972). Conversely, designers working within a module must share knowledge or risk jeopardizing the success of their efforts.

While the technological and organizational consequences of modularity have received a great deal of scholarly attention, the strategic consequences - i.e., how modularity affects competition among firms - have been studied less widely. Rivkin (2000), Pil and Cohen (2006) and Ethiraj et al. (2008) argue that modularity poses a strategic trade-off for innovators. On the positive side, it allows the focal firm to innovate faster and thus stay ahead of would-be imitators. Further advantages, given interfirm compatibility, may be the chance to mix and match modules from different sellers (Matutes and Regibeau, 1988) and to upgrade individual modules selectively (Garud and Kumaraswamy, 1995). An innovator may even invite competitive entry through modularity in order to promote a market segment as a whole (Garud and Kumaraswamy, 1993). On the negative side, modularity makes a firm's products easier to imitate (Ethiraj et al., 2008; Pil and Cohen, 2006; Rivkin, 2000). In this paper, we add to this prior work by looking at how modularity affects the threat of expropriation of IP, and carve out an important distinction between modularity-in-production (which partitions and thus can protect organizational knowledge) and modularity-in-use (which exposes the firm to external competition on modules).

\section{THE BASE CASE: PROTECTING KNOWLEDGE IN ONE-MODULE SYSTEMS}

When someone possesses knowledge and wants to realize its value, he must generally employ individuals and contract with suppliers who will turn that knowledge into a working product or process. But in doing so, the principal must (almost always) reveal his knowledge to those agents, subject to the modular division of the system. The agents, in turn, could set up a rival establishment or reveal the knowledge to competitors (for clarity of exposition, we focus on the first possibility). This threat is well known in law and economics and has been discussed by Teece (1986), Liebeskind (1997), Rønde (2001), and Rajan and Zingales (2001). Organizational knowledge may be protected via trade secrets law and nondisclosure agreements, but such protection is imperfect and its effectiveness varies by jurisdiction (Lemley 2008; Marx, 2011; Oxley, 1999).

\section{Model setup}

We first consider the simplest case: a one-module system, in which each design decision is related to all others. Thus, people working on the module must have unrestricted access to all relevant knowledge in order to address the system's interdependencies. This leaves the principal vulnerable especially when, as we assume, property rights or contracts over knowledge are not enforceable within the governing legal system.

Let the total number of agents who need access to the principal's knowledge be denoted by $N$. The agents fall into two types. The first type, called trustworthy, will under no circumstances defect. The second type, called untrustworthy, will defect if it is in their economic interest to do so. Each agent knows his or her own type, but not the types of the other agents. The probability, $t$, that any given agent is trustworthy is known to both the principal and all agents. We model $t$ as exogenous for the time being. We assume that untrustworthy agents decide independently whether to defect or not. ${ }^{1}$

\footnotetext{
1 The timing of moves is as follows. Each period is divided into two sub-periods. In the first sub-period, agents simultaneously and independently decide whether to defect and the defectors leave. In the second sub-period, the principal learns if any have defected and pays the agents accordingly. The defectors, if any, collect and
} 
Apart from not knowing the other agents' types, all agents have full information about the parameters and the structure of the game. ${ }^{2}$

To keep the analysis tractable and focused on our aim of studying the impact of relationships and modularity, we assume that only two firms can profitably operate in the market. ${ }^{3}$ We define $V$ as the value of the monopoly, and $\alpha V$ as the net value, per firm, of duopoly. A defecting agent who successfully sets up a rival firm appropriates $\alpha V{ }^{4}$ Finally, we assume that $0<2 \alpha V<V$; otherwise an efficient principal would want to create a second establishment of his own accord. In general, $V$ can be ex ante uncertain, in which case $\alpha$ corresponds to a proportionate equity share in the monopoly. There may be reasons to prefer one form of relational contract (e.g., an equity alliance) to others, but in general, those concerns lie outside the scope of our

split their reward. Then, conditional on no defections, the game is repeated. There is no last period of the game, although it may end probabilistically as a result of exogenous events.

2 In his analysis of social norms, Posner (2002) makes similar assumptions about the existence of trustworthy (cooperative) and untrustworthy (uncooperative) agents. He then considers how cooperative agents use conformance with social norms to credibly signal their type. Below, we address the principal's and agents' incentives to invest in better screening or signaling technology, which would help them to increase $t$ among the principal's employees. For now, though, we treat $t$ as exogenous.

3 The general case follows the same logic. However, it is rather complicated because the payments necessary to keep untrustworthy agents loyal are determined recursively. Denote by $F>0$ the fixed cost of establishing a new firm, and by $W_{k}$ the gross value that a $k$-firm oligopoly has for each firm before payments to agents and before paying $F$ (thus, $V$ corresponds to $\left.W_{1}-F\right)$. When $k-1$ agents defect, each starting her own firm, then the market becomes a symmetric $k$-firm oligopoly. Whether such defection is attractive or not depends on $F, W_{k}$, and on the payment $Z_{k} \geq 0$ above the competitive wage that principals make to agents. Assuming that the aggregate gross value $k \cdot W_{k}$ of the oligopoly decreases in $k$, it follows that $W_{k}<W_{1} / k$. Thus, there is a maximum number $k^{\prime}$ such that $W_{k^{\prime}}-F>0$. With $k^{\prime}$ firms in the industry, defection is unattractive and so agent payments will be $0: Z_{k^{\prime}}=0$. For $k<k^{\prime}$, payments necessary to keep agents loyal are determined recursively, starting with $Z_{k^{\prime}-1}=W_{k^{\prime}}-F$. Agent payments at $k=k^{\prime}-1$ determine, together with $W_{k^{\prime}-1}$ and $F$, the net value $X_{k^{\prime}-1}$ of the $\left(k^{\prime}-1\right)$-firm oligopoly to each firm, which in turn determines agent payments required to achieve loyalty in a market with $k^{\prime}-2$ firms. These payments need to fulfill the additional condition that they must deter simultaneous defection by two agents resulting in $k^{\prime}$ firms. Following this logic, the equilibrium outcome for each $k, 1 \leq k \leq k^{\prime}$, is determined. Depending on the (exogenous) values $W_{k}$ and $F$, an intricate sequence of net values $X_{k}$ and corresponding agent payments $Z_{k}$ develops. For some $k$, it may not be worthwhile for the principals to achieve loyalty through agent payments.

${ }^{4}$ Also, when joining an existing competitor, the defecting agent may be able to appropriate the entire value of $\alpha V$, e.g., if several existing firms compete for her knowledge. model (cf. Oxley, 1997, 1999 for an analysis of different contract forms).

\section{The principal's options}

In dealing with the risk of defection, the principal has three options: to do nothing and bank on the possibility that all his agents are trustworthy, license his technology to the highest bidder before hiring agents, or enter into relational contracts with his agents. We analyze each in turn and then determine the principal's best option. For simplicity, we assume all parties are risk neutral, although this assumption is not essential to the results.

\section{Doing nothing, licensing}

If the principal does nothing, then his monopoly is preserved if and only if all $N$ of his agents are trustworthy, which happens with probability $t^{N}$. His expected payoff then is

$$
\Pi_{\text {nothing }}=\left[t^{N}+\alpha\left(1-t^{N}\right)\right] V .
$$

Note that the value of doing nothing declines as $N$, the number of agents, goes up. In effect, each additional agent "in the know" increases the probability that one of them will be untrustworthy.

Alternatively, the principal can, before hiring agents, forgo his monopoly, and license his technology to the highest bidder who will then set up a second competing establishment. By our simplifying assumption that only two firms can profitably operate in the market, the existence of the second establishment makes defection unattractive to agents at both establishments. Assuming more than one bidder and Bertrand competition, we obtain as the value of this option:

$$
\Pi_{\text {licensing }}=2 \alpha V \text {. }
$$

\section{Relational contracts}

As a third option, the principal can set up a self-enforcing relational contract with the agents. Following common practice in economics, we model a relational contract between a principal and his agents as a repeated game in which the principal essentially pays the agents not to defect (Baker et al., 2002; Bull, 1987).

To set up a relational contract with calculative agents, the principal promises to pay each agent a 
bonus above the competitive wage with a present value of $\zeta V$ if nobody defects and 0 otherwise. ${ }^{5}$ The minimum bonus is affected by the principal's need to make the contract self-enforcing. Specifically, if $\zeta<\alpha$ then loyalty by all (untrustworthy) agents cannot be an equilibrium since each can do better by defecting.

To fully specify the game, we must describe what the untrustworthy agents expect to happen when two or more defect. One possibility is that each defector immediately builds a new establishment. Since by assumption, only two establishments profitably operate, the defectors will all incur losses. The game among agents is essentially a game of "chicken," and the unique Nash equilibrium (if $\zeta<\alpha$ ) is for one and only one agent to defect. Alternatively, potential defectors might expect to come together and split the value of the second establishment among themselves. With $\zeta<\alpha$, all untrustworthy agents will defect (since agent payments for those who stay will go down to 0 after defection of one or more others). This game is essentially a prisoner's dilemma (or social dilemma). Each agent gains at the margin by defecting, but in aggregate the defectors are worse off than if they had been loyal.

Interestingly, from the principal's standpoint the design of the relational contract does not depend on the agents' conjectures about the behavior of other agents. Whether the game is chicken or a prisoner's dilemma, if $\zeta<\alpha$, each Nash equilibrium in pure strategies is characterized by one or more untrustworthy agents defecting. And one defection suffices to end the principal's monopoly.

Thus, to bring about an "all-stay" equilibrium, the principal must set $\zeta=\alpha$, paying every untrustworthy agent an amount whose value is equal to the total defection reward, $\alpha V$. And because (by assumption) the principal cannot distinguish between untrustworthy and trustworthy agents, all agents must receive a stream of payments whose value equals $\alpha V$. Thus, the total cost of protecting the principal's knowledge against unauthorized use by agents is $N \alpha V$, and the value of this option is:

$$
\Pi_{\text {payments }}=[1-\zeta N] V=[1-\alpha N] V .
$$

\footnotetext{
5 To keep notation simple, we assume that agents live forever. Assuming a constant probability of dying in each period would keep our results qualitatively unchanged.
}

\section{The principal's best option}

We start by comparing doing nothing to licensing. It is straightforward to show that, for low values of $t$ (an untrustworthy population), the principal will choose licensing, while for high values of $t$, he will hope to preserve the monopoly and do nothing. The following proposition provides more detailed results. All proofs are in the Appendix S1.

Proposition 1: (a) For a one-module system, if (1) property rights and contracts are not enforceable, (2) the principal cannot distinguish between trustworthy and untrustworthy agents, and (3) the defection reward (equivalent to the licensing payment) is $\alpha V$, then the principal should opt to license his knowledge if the percentage of trustworthy agents:

$$
t<t^{\dagger}=\left(\frac{\alpha}{1-\alpha}\right)^{1 / N}
$$

The principal should do nothing if $t>t^{\dagger}$, and is indifferent if $t=t^{\dagger}$. (b) The threshold value $t^{\dagger}$ increases in both $\alpha$ and $N$.

We now compare the payoff obtainable using relational contracts (Equation 3) to those from doing nothing and licensing (Equations 1 and 2, respectively). This leads to:

Proposition 2: (a) Under the same assumptions as Proposition 1, the principal can achieve an all-stay equilibrium in a relational contract by paying each agent an annuity whose present value, denoted $\zeta V$, equals the total defection reward $\alpha V$. (b) Setting up a relational contract is the best policy for the principal if two conditions hold:

$N<\alpha^{-1}-2 ;$ and $t<t^{*}=\left[1-\frac{N \alpha}{1-\alpha}\right]^{1 / N}$

If either condition is violated, then one of the other options (do nothing or licensing) is preferable. (c) The threshold value $t^{*}$ decreases in both $\alpha$ and $N$.

To see how parameter changes affect the principal's best option, we calculated for each pair of options under which conditions one is equal or 
superior to the other. Solving the resulting conditions for $\alpha$, we obtain:

$$
\begin{gathered}
\Pi_{\text {nothing }} \geq \Pi_{\text {payments }} \Longleftrightarrow \alpha \geq \frac{1-t^{N}}{N+1-t^{N}} \\
\Pi_{\text {nothing }} \geq \Pi_{\text {licensing }} \Longleftrightarrow \alpha \leq \frac{t^{N}}{1+t^{N}} \\
\Pi_{\text {payments }} \geq \Pi_{\text {licensing }} \Longleftrightarrow \alpha \leq \frac{1}{N+2}
\end{gathered}
$$

Figure 1 shows the $(t, \alpha)$ parameter space for $N=1$ and $N=5 .^{6}$ We can divide the parameter space into three regions defined by the principal's respective best option. In Region L, licensing is optimal; in Region N, doing nothing; and in Region $\mathrm{P}$, paying agents. The subscript of each label indicates which option is second best. For continuity reasons, the first-best option in a given sub-region is second best in the neighboring sub-region. For example in sub-region $\mathrm{L}_{\mathrm{P}}$, licensing is first best and payments are second best, while in the adjacent sub-region $\mathrm{P}_{\mathrm{L}}$, payments are first best and licensing is second best.

We now establish a basic result that will be useful when we incorporate clan relationships and modularity into the analysis. From Equations 1-3, it is clear that reducing $N$, the number of agents, increases the value of doing nothing and agent payments, while having no effect on the value of licensing. Since the value of each option increases weakly as $N$ decreases, the maximum of these values also increases weakly. We summarize:

\section{Proposition 3: Other things equal, a decline in the number of agents $N$ is either beneficial or value neutral for the principal. With declining $N$, the region in $(t, \alpha)$ parameter space in which licensing is optimal shrinks, while the other two regions expand.}

In the following sections, we show that employing clans and modularizing the product architecture each have the same effect as reducing $N$.

\section{Relationships among agents: clans}

By definition, members of the same clan act together. We can thus assume that the clan follows

\footnotetext{
${ }^{6}$ Note that, even in large firms, the relevant number $N$ of agents
} with access to the principal's knowledge may be quite low. its leader (or, if it does not have one specific leader, behaves as if it had one), and so the probability that any given clan is trustworthy equals the probability $t$ that its leader is trustworthy.

Suppose the $N$ agents are divided into $L$ clans of size $N / L, 1 \leq L \leq N$. Necessarily, $N$ and $L$ are both integers: the fractional parts of $N / L$ can be interpreted as agents who work part-time, $L=N$ is the condition where each agent acts as an individual, and $L=1$ is the condition where all agents belong to the same clan. We assume that defecting clans will split the reward to defection equally among all members of the clan, ${ }^{7}$ and restrict the analysis for simplicity to clans of equal size (we will address the asymmetric case below in our discussion of fairness).

Under these assumptions, employing $L$ clans is mathematically equivalent to employing $L$ agents, while keeping parameters $t$ and $\alpha$ the same. Each clan behaves as a single decision maker, and each can expect a total defection reward equal to $\alpha V$. Thus, the value of doing nothing becomes $\Pi_{\text {nothing, clans }}=\left[t^{L}-\alpha\left(1-t^{L}\right)\right] \cdot V$; the value of licensing is unchanged; and the value of the agent payment strategy becomes $\Pi_{\text {payment, clans }}=[1-\alpha L] \cdot V$.

We can now apply Proposition 3. Since $L<N$, employing clans makes both agent payments and doing nothing more attractive relative to licensing. In the $(t, \alpha)$ parameter space, Regions $\mathrm{N}$ and $\mathrm{P}$ expand while Region L must shrink. If the principal starts and ends the day in Region L, then employing clans is value neutral. In contrast, if, with clans, the principal ends the day in Region $\mathrm{N}$ or Region $\mathrm{P}$, then he is unambiguously better off employing clans vs. employing individualistic agents.

\section{THE IMPACT OF MODULARITY}

The option to hire agents linked by clanship may or may not be available to the principal. However, he has full control over the design of the system subject to technological constraints. In particular, he can design the system in a modular fashion and thus divide the relevant knowledge into separate modules. Importantly, we assume that the principal sells

\footnotetext{
${ }^{7}$ If the clan is hierarchical, such that higher-ranking members are paid more than lower-ranking members, we assume the payments will be similarly apportioned, if the clan defects or does not defect.
} 
only complete systems (rather than individual modules) and is able to protect the system's interfaces such that no third-party products can be attached to the system.

\section{Modeling modules and complementarity}

To start with, consider the simplest case: a symmetric split of the system into $M$ modules, each worth $V / M$. Assume that, as with the entire system, only one competing establishment can be profitably set up for each module. A defecting agent secures the reward $\alpha V / M$, which is also the principal's duopoly payoff from that module. In this situation, the principal's payoffs under the three strategies are given by Equations 1-3 above, with $N$ replaced by $N / M$. Also, $V$ is replaced by $V / M$ and the entire equation multiplied by $M$ : the latter two $M$ s cancel each other out, leaving only $N / M$ in place of $N$. Thus, this type of modularization has the same effect as reducing the number of agents. By Proposition 3, it is beneficial or neutral for the principal.

We now relax the assumption that the overall value of the system is the additive sum of the modules' value. To simplify the analysis and reduce the vast number of combinatorial possibilities, we assume there are two types of defection rewards: a module reward that can be claimed by defectors of any module, and a system reward that can only be claimed if there is a defector in each module. We further assume that the total defection reward for a system of $M$ modules can be expressed as a convex linear combination of the two types:

$$
\begin{aligned}
\text { Total Defection Reward } & \equiv(1-\beta)\left(\sum_{i=1}^{M} \delta_{i}\right) \frac{\alpha V}{M} \\
& +\beta\left(\prod_{i=1}^{M} \delta_{i}\right) \alpha V,
\end{aligned}
$$

where $\beta$ is a number between 0 and 1 , and $\delta_{i}$ equals 1 if at least one agent from module $i$ defected, otherwise $0 .^{8}$ In Equation $7, \beta$ is a parameter that allows us to "tune" the degree to which modules are complementary. If $\beta=0$, then each module has a separate stand-alone value $\alpha V / M$, and the

\footnotetext{
8 For simplicity, we again assume modules are symmetric. Assuming different stand-alone values would simply add another parameter to each term in the summation, but there is no insight to be gained from the added complexity.
}

defectors' total reward is simply the sum of module rewards. In contrast, if $\beta=1$, the modules are strict complements, and all must be present for the defectors to realize any reward at all. For $\beta$ between 0 and 1 , the modules have some stand-alone value, but there is additional value derived from putting all the pieces together.

Our general result is the following:

Proposition 4: When the system is symmetrically split into $M$ modules, with $\beta$ measuring the degree of complementarity between them, then if the share of trustworthy agents is positive and less than one $(0<t<1)$, the values of the principal's various options change as follows:

a The values of doing nothing and of paying agents increase strictly in $M$, the number of modules.

$\mathrm{b}$ These values also increase strictly in $\beta$, the degree of complementarity.

c The value of licensing remains unchanged.

Proposition 4 applies within the bounds $0<t<1$. If $t=1$ (everyone is trustworthy), then the strategy of doing nothing is trivially optimal and its value is invariant to both modularity and complementarity. If $t=0$ (no one is trustworthy), then licensing is better than doing nothing, and is also invariant to modularity and complementarity. However, the strategy of agent payments may dominate licensing in this case: the value of this strategy is strictly increasing in the number of modules and invariant to complementarity.

Thus, in parallel with clans, when modularity is introduced, Region $\mathrm{L}$ in the $(t, \alpha)$ parameter space shrinks while the other two regions ( $\mathrm{N}$ and $\mathrm{P}$ ) expand. If, after modularization, the $(t, \alpha)$ combination lies in Regions N or P, then modularity unambiguously improves the outcome for the principal. Furthermore, as long as some agents are trustworthy, the effect is larger the greater the level of complementarity between modules.

We note that, in a modular system, the principal could also apply hybrid strategies, i.e., treat individual modules differently. Analyzing such strategies in full generality is a rather complex exercise, which we omit in the interest of simplicity. For specific cases, we can show that hybrid strategies are inferior to one of the non-hybrid strategies, and the 


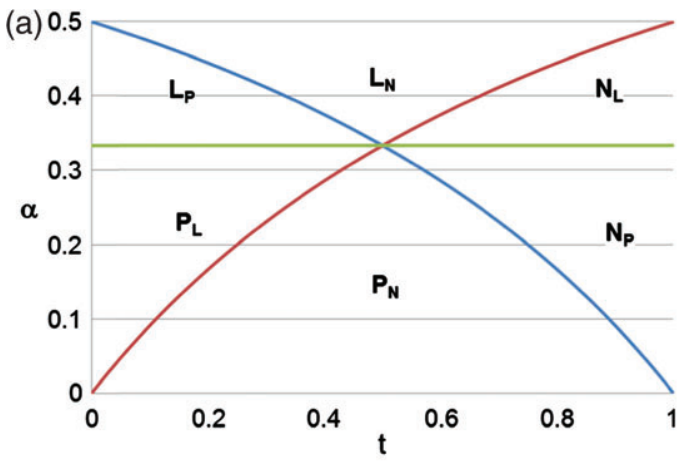

Best option in Region L: licensing; $\mathrm{N}$ : doing nothing; $\mathrm{P}$ : paying agents

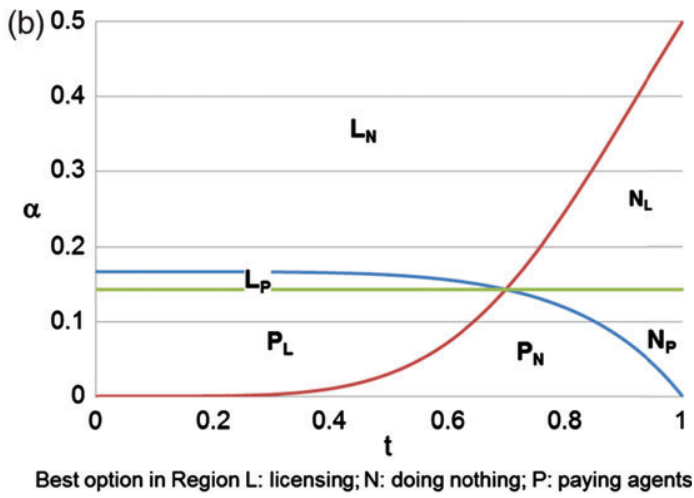

Figure 1. (a, b) The principal's best option as a function of parameters $t$ and $\alpha$

argument provides some indication that a hybrid strategy may never be optimal. ${ }^{9}$

\section{Modularity with clans}

It is possible to have clans within a modular system. We assume that the principal knows the clan structure of his agents and can assign clan members to modules based on this knowledge. Let there be $L$ clans and $M$ modules, where the number of modules is controlled by the principal. To begin with, for simplicity, we also assume that $L=M$, i.e., clan size and module size are matched. (This situation may arise, for example, when a team develops characteristics of a clan through working closely together on one module.)

It is straightforward to show that the principal benefits from having all members of the same clan work on the same module. Clans, we have said, effectively reduce the number of independent decision makers, which increases the value of the do-nothing strategy. They also reduce the per-person defection reward, thus increasing the value of the agent payment strategy. And they do not

\footnotetext{
9 A specific hybrid strategy is for the principal to pay agents in Module 1 not to defect, and do nothing for all other modules. For strong complementarity ( $\beta$ close to 1 ), Module 1 becomes essential for profitable defection (so do all other modules, but those agents do not lose agent payments when they defect). Thus, even if there are defectors in the other modules, this would only cause a minor loss (proportional to $1-\beta$ ) to the principal if he can keep the agents in Module 1 loyal. However, by the same token, these agents will be able to negotiate a large share of the system-level defection reward. This effect vitiates - partly or even entirely, depending on the precise assumptions - the principal's gains from having to pay only $N / M$ instead of $N$ agents. Under specific assumptions, one can show that paying agents in Module 1 only is inferior either to doing nothing or to symmetric agent payments for $\beta=0$, and inferior to the latter for $\beta=1$.
}

change the value of licensing. Hence, by the same reasoning used above, mapping clans onto modules increases the principal's payoff relative to modularity or clans alone in Regions $\mathrm{N}$ and $\mathrm{P}$, and is value neutral in Region L (where modularity and clans have no value anyway).

In contrast, if members of a clan are dispersed through the system, then an untrustworthy clan can be sure there is a willing defector in every module where one of its members works. The per-person payment needed to deter the clan's defection goes up, causing the value of the agent payment strategy to go down. The value of doing nothing also declines compared to a situation without clans because the principal will face system-level competition with higher probability. In effect, a dispersed clan de-modularizes the system to some degree, because clan members can pool their knowledge about different modules and, if they defect, can recreate several modules or even the whole system.

\section{EXTENSIONS}

Our model can be extended in several directions. In this section, we discuss screening of agents and signaling by agents, legal protection of IP, imitation and substitution by third parties, value-increasing modularity, and fairness. We refrain from modeling these extensions formally in order to limit the complexity of the analysis, and instead provide a qualitative discussion of each issue.

\section{Screening and signaling}

An agent's prior exchange relationships may allow the principal to distinguish between trustworthy and 
untrustworthy agents (screening), and may enable the agent to signal her type to the principal. If there is no scarcity of trustworthy agents in the labor market, then the principal will hire only those identified as trustworthy. As long as the selection mechanism works perfectly, the problem of expropriation is solved. However, in identifying trustworthy agents, there will generally be false positives (Granovetter, 1985). In that case, screening and signaling will serve to increase the share of trustworthy agents among the principal's employees: effectively, the $t$ relevant to the principal's decision increases. As a result, the relevant $(t, \alpha)$ combination moves to the right in Figure 1, and the principal's payoff increases with further increases in $t$ as soon as Region N (do-nothing) is reached.

In a modular system, the trustworthiness of the population interacts with system complementarity in an interesting way. As long as some agents are trustworthy $(t>0)$, required agent payments will decline as complementarity increases. Intuitively, a more trustworthy population decreases the probability that an agent from every module will defect, which in turn increases the probability that the "system value" will be captured by the principal. Thus, in Regions $\mathrm{N}$ and $\mathrm{P}, t$ and $\beta$ are strict complements in the sense of Milgrom and Roberts (1990): an increase in one makes increasing the other more valuable. ${ }^{10}$

The premise that trustworthy agents can be identified through their prior exchange relationships has the additional implication that an agent's behavior with the focal principal will affect her reputation, and hence her ability to achieve attractive wages in the future (e.g., Hannah, 2005). We can account for this effect in our model by reducing the payoff to defectors by a reputational penalty. The agent payment strategy becomes less costly, hence more attractive to the principal, while doing nothing and licensing remain unaffected. Thus, Region $\mathrm{P}$ in the parameter space expands while the other regions contract.

\section{Legal protection of intellectual property}

A perfect legal system would enable the principal to obtain and enforce IP rights and contracts. However,

\footnotetext{
${ }^{10}$ Within regions $\mathrm{N}$ and $\mathrm{P}$, this fact can be demonstrated by simple calculus. If the principal switches regions, it follows from the fact that strict complementarity holds for the second-best strategy, hence must $a$ fortiori hold for the first-best strategy.
}

although worldwide IP rights have been strengthened by the recent TRIPS agreement, they are still weakly enforced in many emerging economies (Branstetter et al., 2011; Kyle and McGahan, 2009). And even in developed economies, there is generally some uncertainty about the enforceability and scope of IP protection (Lemley and Shapiro, 2007).

In our model, legal protection of intellectual property would reduce the payoff to defection because of the possibility of legal sanctions such as fines or imprisonment. ${ }^{11}$ Any reduction in defection rewards makes the agent payment strategy more attractive, and a reduction that turns the reward negative makes doing nothing the best option. The value of licensing remains unchanged. Thus, as with the introduction of clans and modularity, a legal system that protects intellectual property expands Regions $\mathrm{N}$ and $\mathrm{P}$ at the expense of Region $\mathrm{L}$.

In the limit, with a perfect legal system, no agent perceives any benefit to defection, and the do-nothing strategy prevails everywhere in the parameter space. Licensing, clans, relational contracts, and modularity are all irrelevant in this (admittedly unrealistic) world.

\section{Imitation or substitution by third parties}

Imitation or substitution by third parties may also threaten the principal's monopoly. If their identity is unknown, the principal cannot include such parties in any relational contract. But if imitation or substitution by external agents is likely, the value of the monopoly will decrease.

Extending our model to address the possibilities of imitation and substitution leaves the value of licensing unchanged, since by assumption only two firms can profitably operate in the market. In contrast, the values of doing nothing and of paying agents go down, since the principal's monopoly faces an additional (even if probabilistic) threat. Thus Region L expands, while Regions $\mathrm{N}$ and $\mathrm{P}$ shrink.

It has been argued that modularity increases the risk of imitation or substitution of individual modules (Ethiraj et al., 2008; Pil and Cohen, 2006; Rivkin, 2000). However, two technically distinct types of modularity have different effects on

\footnotetext{
${ }^{11}$ In the United States, theft of trade secrets is the only violation of intellectual property law that carries potential criminal sanctions (Lemley, 2008).
} 
module-level imitation and substitution. On the one hand, systems that are "modular-in-use" have external points of attachment (often called interfaces) that give users the ability to reconfigure their systems by replacing and adding new modules (Baldwin and Clark, 2000; Sako and Murray, 1999). In such systems, modules can be attached separately, hence bought and sold separately. Unless the principal manages to keep these interfaces proprietary, competition from imitators or substitutors may emerge on the module level. Even modules whose stand-alone value is low (i.e., their level $\beta$ of complementarity to the system is high) may be sold separately by third parties, to be attached to the principal's system. In that case, however, the principal may (at least in the case of imitation) still capture most of the value if he maintains proprietary control of those core parts of the system to which the third party module is complementary, and prices his own version of that module at marginal cost.

However, a system can be "modular-inproduction," but not modular-in-use. Here, production is divided up into discrete process modules, but the system will be sold to users as a single, closed system with no external interfaces. Users cannot then mix and match modules, and there will be no market for modules (Fixson and Park, 2008). Imitators can at best capture the stand-alone value of a module, which is low (possibly 0) in systems characterized by a high level of complementarity.

We thus arrive at an important strategic distinction between these two types of modularity. Modularity-in-use indeed increases the risk of imitation and substitution as argued by Rivkin (2000), Pil and Cohen (2006), and Ethiraj et al. (2008). While the principal may try to keep interfaces proprietary, this approach may well fail. In contrast, modularity-in-production can mitigate the risk of knowledge appropriation by agents, without exposing the modules to imitation or substitution. This is not the best of both worlds, however: a system with no external interfaces necessarily prevents users from exercising reconfiguration options, which they may see as very valuable. System designers must weigh the positive impact of users' reconfiguration options on demand against the potential leakage of value to third-party providers of modules.

The key point is that modularity-in-production and modularity-in-use are distinct and have different strategic consequences. A firm may elect to have one or the other, both, or neither.

\section{Value-increasing modularity}

Modularization may increase system value and/or be costly - two effects we have ignored so far. A value increase would affect both the value of monopoly and that of defection, and so can be addressed in our model, quite simply, by scaling the overall value, $V$. Similarly, a cost of modularization can be accounted for by a fixed cost term. Both changes would leave the mechanics and results of our model qualitatively unaffected.

Notice, however, that if the value of the monopoly, $V$, increases, then the dollar value of defection rewards increases as well. To counterbalance the higher rewards, agent payments must go up in absolute terms. In other words, a value-increasing modularization can have the effect of disequilibrating preexisting relational contracts, unless the principal adjusts agent payments to reflect the new, higher value of the system. We will return to this point in our discussion of System/360 below.

\section{Fairness}

In designing a relational contract, rational choice theory recommends paying different groups of employees differently if they differ in terms of their share of trustworthy agents or the value of the module they are working on. The same recommendation arises if the principal employs clans of different sizes or a mixture of clans and individual agents. In our model, members of larger clans would be paid less than those in smaller clans, and any clan member would be paid less than an individual.

However, agent behavior may not be fully consistent with rational choice theory. This is particularly so for clans which are, by definition, groups of individuals who are socialized to obey the clan's norms (Ouchi, 1980: 132). Two very common norms, both borne out in laboratory experiments, are fairness and reciprocity. For example numerous laboratory experiments have shown that human subjects will punish someone who is unfair to them, even if it is against their immediate interest to do so, a behavior known as negative reciprocity (Gächter and Fehr, 2002; Prasnikar and Roth, 1992).

If agents' efforts and skill levels are the same, then paying some agents more than others is patently unfair. Thus, even though it may be rational and consistent with the Nash equilibrium to set up differential payments to prevent defection, the principal takes risks by doing so. Perceived unfairness can set in motion retaliatory strategies that are 
not individually or collectively rational. Individuals or clans might defect even though it is to their own loss.

That said, agents are not entirely irrational either. They may accept a certain level of perceived unfairness if it is in their own or their clan's interest. The principal can also take care that differential payments remain confidential (a common policy in many firms), or can justify them via organizational boundaries or nominally different job assignments.

\section{EXAMPLES}

In this section, we offer examples from practice that may help to clarify the assumptions, results, and limitations of our model. We begin with cases in which relational contracts and/or clans have been used to encourage loyalty and thus protect organizational secrets. We then discuss cases in which modularity together with complementarity have been used for this purpose. Our last example describes a value-creating modularization that upset the preexisting relational contract between company and employees and triggered a large number of employee defections.

\section{Relational contracts, clans, screening, and signaling}

In the United States in the nineteenth century, the law regarding trade secrets protected documents and equipment, but not the knowledge in the heads of departing employees. Some employers did not hesitate to use relational contracts to ensure loyalty. For example, Massachusetts mill owner, Samuel Slater, paid his key employees higher wages to prevent their "aiding and assisting another mill" (Fisk, 2001: 467).

\section{Irénée Du Pont}

Not all mill owners were eager to use this practice, however. For example, in the early nineteenth century, Irénée Du Pont founded an eponymous company to make gunpowder. Workers at Du Pont mills had valuable knowledge about powder-making processes and thus other mill owners sometimes tried to lure them away with offers of higher wages (Fisk, 2001). Notably, Du Pont did not match these outside offers. He was very conscious of the high cost of paying all workers their defection reward, writing to another mill owner, "More than twenty other hands who ... possess as much information as the ones you wish to bribe must naturally suppose they ought to receive the same exorbitant wages" (ibid., p. 475).

In terms of our model, Du Pont preferred doing nothing to setting up a relational contract with his workers. However, there is indirect evidence that he relied in part on the embeddedness of his workers in kinship groups and communities that may have functioned as clans. Du Pont family members and their workers lived and worked side by side in relatively remote communities. ${ }^{12}$ A defector would have to leave his home, friends, and extended family behind and would suffer the condemnation not only of the Du Ponts, but of his fellow workers who remained loyal to the firm.

\section{Liftouts}

Within organizations, people who work closely together may develop close social ties. For example, it is not uncommon for individuals to stay in an organization despite financially attractive outside offers because of their strong sense of loyalty towards colleagues, coworkers, and bosses. It is also possible for a group of employees with close ties to leave as one body. For example, when John Merriwether left Salomon Brothers, six other managing directors followed, to become partners in Merriwether's new firm, LTCM (Lowenstein, 2000).

The hiring away of an organizational unit or team is known as a liftout. According to Groysberg and Abrahams (2006), liftouts are common in knowledge-based service businesses. A team that already knows how to work together can deliver better performance sooner than an equally skilled group of unconnected individuals. Such teams generally have common beliefs and mutually supportive social interactions. Whether they stay or leave the company, they act "as one" for the benefit of the group. Thus, they conform to Ouchi's definition of a clan.

\section{Modularity}

We turn now to cases where modularity, in conjunction with complementarity, has been used to protect intellectual property.

12 One does not locate gunpowder factories in the middle of cities. 


\section{Porcelain}

In the Introduction of this paper, we described how Elector Frederick Augustus of Saxony used modularity to maintain a monopoly on European porcelain. ${ }^{13}$ Ironically, Augustus could not rely on law-his law - to enforce intellectual property rights: a defector had only to ride as far as the nearest border (a relatively short distance) to escape his jurisdiction. Initially Augustus managed to keep all the essential knowledge in the head of one man whom he imprisoned. Subsequently, he split the knowledge of porcelain paste and glaze between two individuals, thus modularizing the porcelain-making process. By Proposition 4, the modularization made it easier to trust those individuals or set up self-enforcing relational contracts to prevent their defection. The modularization was particularly effective because the two process modules were highly complementary: glazed porcelain products were much more valuable than unglazed porcelain or glaze alone.

\section{Radial tires}

Moving into the twentieth century, Liebeskind (1997) describes a similar split of production processes and knowledge related to making radial tires:

During the 1960s, Michelin had a monopoly on knowledge relating to the production of high quality steel-belted radial tire manufacturing. In order to preserve this monopoly, manufacturing was divided into two separate processes: steel belt manufacturing, and tire production. Employees were not rotated between these manufacturing processes in a deliberate effort to restrict the number of employees that had knowledge about both processes. As a result, only a handful of very

\footnotetext{
13 Augustus' motivations in owning a porcelain factory were complex. As a monarch, he maintained a large personal collection of porcelain objects and took the best pieces for himself. $\mathrm{He}$ also used the factory as a source of revenue. Both as a collector and as the sole owner of the factory, he was eager to maintain a monopoly over the porcelain-making process in Europe (Gleeson, 1998). Today, his collection may be seen at the Zwinger Palace in Dresden http://www.skd.museum/ en/museums-institutions/zwinger-with-semperbau/porzellansam mlung/ (viewed December 24, 2013).
}

senior managers within Michelin were knowledgeable about the entire manufacturing process ( p. 645).

As in the case of porcelain, the two process modules were complementary, although specific knowledge of each may have had some stand-alone value.

\section{Practices in emerging economies}

Emerging economies are an interesting source of examples for us because intellectual property rights are generally not well protected in these settings. As a result, the actions managers take to protect organizational secrets are more stark and visible.

Based on 120 interviews conducted in Brazil and Mexico in the 1980s, Sherwood (1990) reports that the following tactics were used to discourage the "predatory hiring" by competitors of employees with valuable knowledge: (1) Access to corporate technology was limited to family members or trusted employees. (2) Attractive housing was offered to key technical employees. (3) Critical technologies were worked on only by expatriate employees who had long-term career paths with the international parent firm. (4) New hires were exposed to only a small part of the overall operation and left in that role for several years, until they were viewed as trustworthy. (5) The founder alone knew the whole process, but a few life-long employees were permitted to know discrete parts. Note that practice (1) makes use of clans, (2) and (3) are forms of relational contracting, and (4) and (5) combine screening with modularity.

Zhao (2006) argues that modularity and complementarity have been used to protect the value of multinational companies' R\&D across international boundaries. To protect the value of their $R \& D$, she reasoned, multinationals can divide work to allocate projects with little stand-alone value to subsidiaries in countries with weak IP protection. She then showed that patents obtained by subsidiaries in countries with weak IP rights have more value in conjunction with patents owned by the parent company than those owned by third parties.

Relatedly, in a series of interviews, Quan and Chesbrough (2010) found that multinational managers located projects with little stand-alone value in China because of concerns about weak IP protection in that country. The fact that the projects had little stand-alone value reduced defection rewards, 
hence the salaries needed to keep employees loyal. The multinationals could thus take advantage of the lower cost of conducting research in China without compromising returns on their $R \& D$ investments.

\section{IBM System $/ \mathbf{3 6 0}$}

In general, our theoretical results indicate that modularity can be used to reduce the cost and/or risk of agents' expropriating valuable IP. How can these results be reconciled with the example of System/360, cited in the Introduction, where modularization appeared to trigger a large number of employee defections with concomitant loss of IP? The answer to this conundrum is twofold.

First, the example does not fulfill our assumption that the principal sells only complete systems and hides interfaces to prevent third parties from attaching modules to the system. Rather, to provide customers with configuration options, IBM sold its modules separately and exposed modular interfaces. This modularity-in-use enabled customers to integrate modules acquired from third parties into IBM systems. Thus, imitators could compete at the module level, without offering whole systems: the configurable system offered accessible points of attachment for such third-party modules (Fixson and Park, 2008). In contrast, Augustus of Saxony did not sell unglazed porcelain, nor did Michelin sell steel belts separately from tires.

Second, largely because of the options it gave to customers, System/360 was a huge market success (Baldwin and Clark, 2000). Thus suddenly, "people with knowledge of IBM technology and business plans [were] worth more outside the company ... than inside" (Pugh et al., 1991: 491). The result was "defections en masse" (ibid. p. 490). Lured by new start-ups, a significant number of IBM engineers, including some of the most creative and influential, left the company to join firms that were in direct competition with IBM. These defections can be understood as a response to the disequilibrium caused by a value-increasing modularization of very large proportions.

Could IBM have prevented these defections? According to our model, it could have changed the relational contract to match the defection rewards. However, at the time, IBM's senior executives did not think in terms of defection rewards and agent payments, but in terms of trust and loyalty to the company. Thus, IBM's managers elected to do nothing, and simply let the defectors go. Anticipatory licensing and/or an appropriate increase in loyalty payments, in line with our model, might have been advantageous to IBM. (In this regard, it is noteworthy that IBM made extensive use of anticipatory licensing when it introduced the IBM PC in 1981.)

\section{CONCLUSION}

A principal who derives rents from exclusive knowledge faces the threat of expropriation by agents. In this paper, we investigated the impact of modularity on intellectual property protection by formally modeling this threat. In our model, the principal has three options: doing nothing, licensing the focal IP ex ante, and paying agents (via a relational contract) to prevent their defection. We showed that the principal can influence the value of these options by modularizing the technical system and by hiring clans of agents, thus exploiting relationships among them. His optimal choice depends on a number of external parameters - the number of agents, the percentage of trustworthy agents, the intensity of competition, the existence and size of clans, the number of modules, and the degree of complementarity in the system. Extensions of the model can be used to understand the effects of screening and signaling in the hiring process, legal protection of intellectual property, imitation and substitution, disequilibrating changes in the value of knowledge, and social norms of fairness. We also presented examples to show how managers arrive at a strategy in practice.

We contribute to the theory of profiting from innovation in several ways. First, we show how the innovator's best choice of action against expropriation by agents derives from characteristics of both the technical system (modularity, complementarity, exposure of modular interfaces) and the surrounding society (clans, social norms, methods of screening and signaling). We go beyond earlier work (Rajan and Zingales, 2001; Rønde, 2001) in considering a mixed population of trustworthy and untrustworthy agents. This links our analysis to the literature on screening and signaling, with the finding that imperfect screening has an effect only if the principal's best option, with screening, is to trust the agents. Second, we extend prior work by showing how the innovator 
can use clans and modularity to increase his profits. Importantly, we carve out the distinction between modularity-in-use, which facilitates imitation and substitution, and modularity-in-production, which protects against expropriation by agents. If a system designer can achieve modularity-in-production without modularity-in-use and prevent third parties from accessing system interfaces, then modularity works to protect valuable IP. Third, we show how clans and the modular architecture of the system interact to either reinforce or cancel each other. This interaction implies that an analysis of modularity alone will be misleading if clans are present in the focal organization. Finally, we show how social relationships and norms of fairness affect the normative implications of an analysis based on rational choice theory. In particular, the recommendations of rational choice theory will yield the opposite of the intended outcomes if norms of fairness and reciprocity govern the actions of agents.

Although the details determining the best strategies are complex, the implications for managers are relatively straightforward. The fundamental choices are (1) to protect the knowledge or not, and (2) to trust the agents or not. Relational contracts, that is, paying selected agents not to defect, makes it possible to protect knowledge and maintain a monopoly when agents are relatively untrustworthy. Clans, modularity, complementarity, and a legal system all serve to lower the cost and increase the value of this strategy. Trusting one's agents - what we have called doing nothing - is the most valuable course of action if it works, but is a risky strategy because trust can always be betrayed. Better screening and signaling technologies make it easier for the principal to trust his agents, but some residual risk always remains.

Our model has a number of limitations. Most importantly, we have presented agent payments and trust as stark alternatives. However, given norms of fairness and reciprocity, the boundary between these strategies tends to blur. Specifically, trustworthy agents may expect "fair" treatment from the principal, where fair entails some sharing of the value of the enterprise. In effect, $t$ may be an implicit function of the agent payment parameter $\zeta$. Then, in an abstract sense, the principal's problem will be to determine a feasible and effective combination of $t$ and $\zeta$. It is certainly possible to set up a model of this type, but the $t(\zeta)$ function, if it exists, is not one we know much about.
Another limitation consists in our simplifying assumption that only two firms can profitably operate in the market. Relaxing this assumption such that $k^{\prime}$ firms are viable introduces a number of additional effects. First, to be effective, agent payments must be high enough to make, for any $k$ with $2 \leq k \leq k^{\prime}$, the setup of $k-1$ competing establishments unattractive. Since (cf. Footnote 3) the net value per firm of participation in a market with $k$ firms does not necessarily decrease in $k$, the principal has in general $k-1$ constraints to evaluate. Second, the principal has to assess the attractiveness of licensing to any number of $k-1$ firms. Both considerations depend on the attractiveness of being active in a $k$-firm oligopoly, which in turn depends on agent payments required to prevent defection from the oligopoly. Hence, the general problem is both recursive and combinatorially explosive. In addition, in a $k$-firm oligopoly, a social dilemma arises between the firms, since licensing by one firm exerts a negative externality on all others (Arora and Fosfuri, 2003). However, despite these complications, our main results regarding the effects of modularity, clans, complementarity, and social norms of fairness will hold up since the logic of these effects is independent of the number of firms that can operate in the market.

Lastly, there are three potential routes to testing the model. The first is to conduct surveys and interviews, as in Sherwood (1990) and Poppo and Zenger (2002). These can determine whether some of the basic correlations predicted by the model, for example, a switch from agent payments to doing nothing as the perceived trustworthiness of employees increases, are observed in cross-section. However, such tests will be hampered by the fact that there is no guaranty of consistency in the perceptions of managers in different firms and countries. A second approach is to conduct case studies of events such as the introduction of System/360. However such events are rare and generally subject to multiple causal explanations. Finally, laboratory experiments can be used to test whether differences in $t$, $\alpha$, or $N$ lead to strategy choices consistent with the model's predictions. In other words, using intuitive reasoning alone, do individuals make choices that are consistent with the predictions of the model? And what, if any, role do norms of fairness and reciprocity play in determining their choices? The most promising route we think involves a combination of surveys, interviews, and lab experiments to 
determine how managers reason practically about protecting organizational secrets.

\section{ACKNOWLEDGEMENTS}

We are grateful to Ron Adner, Oliver Alexy, Juan Alcacer, Ramon Casadesus-Masanell, Susan Cohen, Robert Gibbons, Venkat Kuppuswamy, Robert Merges, Matt Marx, Christina Raasch, Andrew Torrance, Eric van den Steen, Eric von Hippel, Jason Woodard, Dennis Yao, and Minyuan Zhao, as well as participants in seminars and workshops at the Tuck School of Business, Harvard Business School, Imperial College Business School, London Business School, MIT, Ross School of Business at the University of Michigan, and UNC Kenan-Flagler Business School for many helpful comments on earlier drafts of this paper. Very special thanks go to the associate editor Anita $\mathrm{McGahan}$ and two anonymous referees for rigorous and challenging reviews, which led to significant improvements in both the theoretical arguments and the modeling approach. Support from the Harvard Business School Division of Research and TUM School of Management at Technische Universität München is gratefully acknowledged.

\section{REFERENCES}

Alvesson M, Lindkvist L. 1993. Transaction costs, clans and corporate culture. Journal of Management Studies 30(3): 427-452.

Anton JJ, Yao DA. 2005. Markets for partially contractible knowledge: bootstrapping versus bundling. Journal of the European Economic Association 3(2/3): 745-754.

Arora A, Fosfuri A. 2003. Licensing the market for technology. Journal of Economic Behavior \& Organization 52: $277-295$.

Arora A, Merges RP. 2004. Specialized supply firms, property rights and firm boundaries. Industrial and Corporate Change 13(3): 451-475.

Arrow KJ. 1962. Economics of welfare and the allocation of resources for invention. In The Rate and Direction of Inventive Activity, Nelson RR (ed). Princeton University Press: Princeton, NJ; 609-625.

Baker G, Gibbons R, Murphy KJ. 2002. Relational contracts and the theory of the firm. Quarterly Journal of Economics 117: 39-84.

Baldwin CY. 1983. Productivity and labor unions: an application of the theory of self-enforcing contracts. The Journal of Business 56(2): 155-185.

Baldwin CY, Clark KB. 2000. Design Rules, Vol. 1: The Power of Modularity. MIT Press: Cambridge, MA.

Barney JB. 1991. Firm resources and sustained competitive advantage. Journal of Management 17: 99-120.
Bjørnskov C. 2007. Determinants of generalized trust: a cross-country comparison. Public Choice 130(1-2): $1-21$.

Branstetter LG, Fisman R, Foley CF, Saggi K. 2011. Does intellectual property reform spur industrial development. Journal of International Economics 83(2011): $27-36$.

Brynjolfsson E. 1994. Information assets, technology and organization. Management Science 40(12): $1645-1662$.

Bull C. 1987. The existence of self-enforcing implicit contracts. Quarterly Journal of Economics 102(1): 147-159.

Coase RH. 1937. The nature of the firm. Economica 4(16): 386-405.

Dyer JH, Singh H. 1998. The relational view: cooperative strategy and sources of interorganizational competitive advantage. Academy of Management Review 23(4): $660-679$

Ethiraj SK, Levinthal D, Roy R. 2008. The dual role of modularity: innovation and imitation. Management Science 54(5): 939-955.

Ferguson CH, Morris CR. 1993. Computer Wars: How the West Can Win in a Post-IBM World. Times Books: New York.

Fisk C. 2001. Working knowledge: trade secrets, restrictive covenants in employment, and the rise of corporate intellectual property, 1800-1920. Hastings Law Journal 52(2): 441-528.

Fixson SK, Park J-K. 2008. The power of integrality: linkages between product architecture, innovation and industry structure. Research Policy 37(8): 1296-1316.

Gächter S, Fehr E. 2002. Fairness in the labour market? A survey of experimental results. Zurich IEER Working paper 114. Available at SSRN: http://ssrn.com. ezp-prod1.hul.harvard.edu/abstract $=310619$ (accessed 15 January 2014).

Garud R, Kumaraswamy A. 1993. Changing competitive dynamics in network industries: an exploration of sun microsystems' open systems strategy. Strategic Management Journal 14: 351-369.

Garud R, Kumaraswamy A. 1995. Technological and organizational designs for realizing economies of substitution. Strategic Management Journal 16: 93-109.

Gibbons R, Henderson R. 2012. Relational contracts and organizational capabilities. Organization Science 23: $1350-1364$.

Gleeson J. 1998. The Arcanum: The Extraordinary True Story. Warner Books: New York.

Granovetter M. 1985. Economic action and social structure: the problem of embeddedness. American Journal of Sociology 91(3): 481-510.

Greif A. 1998. Self-enforcing political systems and economic growth: late medieval Genoa. In Analytic Narratives, Bates R, Greif A, Levi M, Rosenthal J-L, Weingast BR (eds). Princeton University Press: Princeton, $\mathrm{NJ} ; 23-63$.

Grossman SJ, Hart OD. 1986. The costs and benefits of ownership: a theory of vertical and lateral integration. Journal of Political Economy 94(4): 691-719. 
Groysberg B, Abrahams R. 2006. Lift outs: how to acquire a high-functioning team. Harvard Business Review 84(12): $133-140$.

Hannah DR. 2005. Should I keep a secret? The effects of trade secret protection procedures on employees' obligations to protect trade secrets. Organization Science 16(1): $71-84$.

Hart OD, Moore J. 1990. Property rights and the nature of the firm. Journal of Political Economy 98(6): 1119-1158.

von Hippel E. 1990. Task partitioning: an innovation process variable. Research Policy 19: 407-418.

Johnson JP, Korsgaard MA, Sapienza HJ. 2002. Perceived fairness, decision control, and commitment in international joint venture management teams. Strategic Management Journal 23: 1141-1160.

Kreps D. 1990. Corporate culture and economic theory. In Perspectives on Positive Political Economy, Alt J, Shepsle K (eds). Cambridge University Press: Cambridge, UK; 90-143.

Kyle M, McGahan A. 2009. Investments in pharmaceuticals before and after TRIPS. Review of Economics and Statistics 94(4): 1157-1172.

Langlois RN. 2002. Modularity in technology and organization. Journal of Economic Behavior and Organization 49(1): 19-37.

Langlois RN, Robertson PL. 1992. Networks and innovation in a modular system: lessons from the microcomputer and stereo component industries. Research Policy 21: $297-313$.

Lemley MA. 2008. The surprising virtues of treating trade secrets as IP rights. Stanford Law Review 61: 311-353.

Lemley MA, Shapiro C. 2007. Patent holdup and royalty stacking. Texas Law Review 85: 1991-2049.

Liebeskind JP. 1997. Keeping organizational secrets: protective institutional mechanisms and their costs. Industrial and Corporate Change 6: 623-663.

Lowenstein R. 2000. When Genius Failed: The Rise and Fall of Long-Term Capital Management. Random House: New York.

Macneil IR. 1978. Contracts: adjustment of long-term economic relations under classical, neoclassical, and relational contract law. Northwestern University Law Review 72: 854-905.

Macneil IR. 1985. Relational contract: what we do and do not know. Wisconsin Law Review 1985: 483-525.

Macneil IR. 1987. Relational contract theory as sociology: a reply to Professors Lindenberg and de Vos. Journal of Institutional and Theoretical Economics 143(2): $272-290$.

Marx M. 2011. The firm strikes back: non-compete agreements and the mobility of technical professionals. American Sociological Review 76(5): 695-712.

Maskus KE. 2000. International Property Rights in the Global Economy. Institute for International Economics: Washington, DC.

Matutes C, Regibeau P. 1988. 'Mix and match': product compatibility without network externalities. RAND Journal of Economics 19: 221-234.

Mazar N, Amir O, Ariely D. 2008. The dishonesty of honest people: a theory of self-concept maintenance. Journal of Marketing Research 45(6): 633-644.
Mead C, Conway L. 1980. Introduction to VLSI Systems. Addison-Wesley: Reading, MA.

Meier S. 2006. A survey of economic theories and field evidence on pro-social behavior. Working paper series // Federal Reserve Bank of Boston, No. 06-6.

Milgrom P, Roberts J. 1990. The economics of manufacturing: technology, strategy and organization. American Economic Review 80(3): 511-528.

Ouchi WG. 1980. Markets, bureaucracies, and clans. Administrative Science Quarterly 25: 129-141.

Oxley JE. 1997. Appropriability hazards and governance in strategic alliances: a transaction cost approach. Journal of Law, Economics, and Organization 13(2): 387-409.

Oxley JE. 1999. Institutional environment and the mechanisms of governance: the impact of intellectual property protection on the structure of inter-firm alliances. Journal of Economic Behavior \& Organization 38(3): 283-309.

Parnas DL. 1972. On the criteria to be used in decomposing systems into modules. Communications of the ACM 15: 1053-1058.

Pil FK, Cohen SK. 2006. Modularity: implications for imitation, innovation, and sustained competitive advantage. Academy of Management Review 31(4): 995-1011.

Poppo L, Zenger T. 2002. Do formal contracts and relational governance function as substitutes or complements? Strategic Management Journal 23(8): $707-725$.

Poppo L, Zhou KZ, Zenger TR. 2008. Examining the conditional limits of relational governance: specialized assets, performance ambiguity, and long-standing ties. Journal of Management Studies 45(7): 1195-1216.

Posner EA. 2002. Law and Social Norms. Harvard University Press: Cambridge, MA.

Prasnikar V, Roth AE. 1992. Considerations of fairness and strategy: experimental data from sequential games. Quarterly Journal of Economics 107(3): $865-888$.

Pugh EW, Johnson LR, Palmer JH. 1991. IBM's 360 and Early 370 Systems. MIT Press: Cambridge, MA.

Quan X, Chesbrough H. 2010. Hierarchical segmentation of R\&D process and intellectual property protection: evidence from multinational R\&D laboratories in China. IEEE Transactions on Engineering Management 57(1): 9-21.

Rajan R, Zingales L. 2001. The firm as a dedicated hierarchy: a theory of the origin and growth of firms. Quarterly Journal of Economics 116(1): 805-851.

Rivkin JW. 2000. Imitation of complex strategies. Management Science 46: 824-844.

Rønde T. 2001. Trade secrets and information sharing. Journal of Economics \& Management Strategy 10(3): $391-417$.

Rotter JB. 1980. Interpersonal trust, trustworthiness, and gullibility. American Psychologist 35(1): 1-7.

Sako M. 1998. Does trust improve business performance? In Organizational Trust: A Reader, Kramer R (ed). Oxford University Press: Oxford, UK; 88-117.

Sako M, Murray F. 1999. Modules in design, production and use: implications for the global automotive industry. In Paper Presented at the Fall Meeting of the 
International Motor Vehicle Program (IVMP), Annual Sponsors Meeting, 5-7 October 1999, Cambridge, MA.

Sanchez R, Mahoney JT. 1996. Modularity, flexibility, and knowledge management in product and organizational design. Strategic Management Journal, Winter Special Issue 17: 63-76.

Schilling MA. 2000. Toward a general modular systems theory and its application to interfirm product modularity. Academy of Management Review 25: 312-334.

Sherwood RM. 1990. Intellectual Property and Economic Development. Westview Press: Boulder, CO.

Simon HA. 1962. The architecture of complexity. Proceedings of the American Philosophical Society 106: 467-482.

Teece DJ. 1986. Profiting from technological innovation: implications for integration, collaboration, licensing and public policy. Research Policy 15: 285-305.

Teece DJ. 2000. Strategies for managing knowledge assets: the role of firm structure and industrial context. Long Range Planning 33(1): 35-54.

Telser LG. 1980. A theory of self-enforcing agreements. Journal of Business 53(1): 27-44.
Ulrich KT, Eppinger SD. 1994. Product Architecture, Methodologies for Product Design and Development. McGraw-Hill: New York.

Uzzi B. 1997. Social structure and competition in interfirm networks: the paradox of embeddedness. Administrative Science Quarterly 42(1): 35-67.

Williamson OE. 1993. Calculativeness, trust, and economic organization. Journal of Law and Economics 36: 453-486.

Yamagishi T, Yamagishi M. 1994. Trust and commitment in the United States and Japan.

Zhao M. 2006. Conducting R\&D in countries with weak intellectual property rights protection. Management Science 52(8): 1185-1199.

\section{SUPPORTING INFORMATION}

\section{Additional supporting information may be found in the online version of this article:}

Appendix S1. Modularity and intellectual property protection. 